\title{
İslam Tetkikleri Dergisi
}

\section{التقريب المختصر لمسألتي تعجيل وتأجيل الزكاة مع بيان الحكم والأثر}

\section{A Brief Approximation of The Issues of Accelerating and Deferring Zakat, with an Explanation of The Ruling and The Effect}

Mohanad Mustafa Aqaileh ${ }^{1}$ (D), Ibrahim Abdalhaleem Obada ${ }^{2}$ ()

Sorumlu yazar/Corresponding author:

Mohanad Aqaileh, Yarmouk University, Irbid, Jordan

E-posta: mohanadaqaileh1@gmail.com ORCID: 0000-0003-4701-7777

${ }^{2}$ Ibrahim Abdalhaleem Obada, Yarmouk University, Irbid, Jordan

ORCID: 0000-0003-3519-8507

Başvuru/Submitted: 07.02.2021 • Revizyon Talebi/Revision Requested: 10.08.2021 • Son Revizyon/Last Revision Received: 16.08 .2021 • Kabul/Accepted: 16.08 .2021

Atıf/Citation: Aqaileh, Mohanad Mustafa \& Obada, Ibrahim Abdalhaleem. A Brief Approximation of The Issues of Accelerating and Deferring Zakat, with an Explanation of The Ruling and The Effect. Islam Tetkikleri Dergisi-Journal of Islamic Review 11/2 (Eylül 2021): 1013-1023.

https://doi.org/10.26650/iuitd.2021.876089

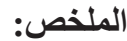

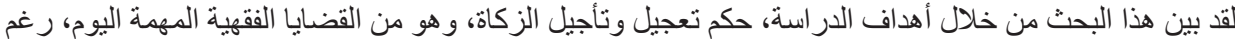

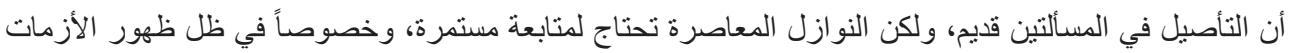

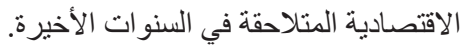

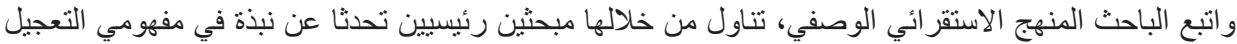

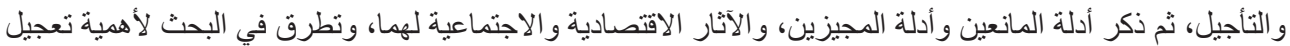

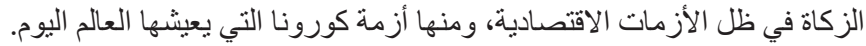

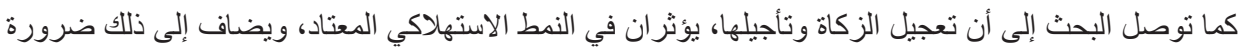

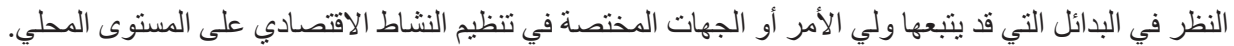

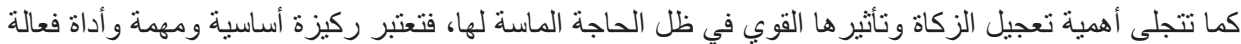

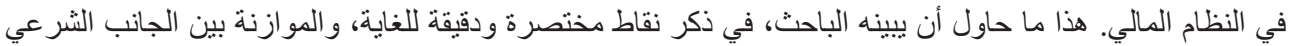


للمسألتين و الجانب الاقتصادي. وخلصت الدر اسة إلى أن تعجيل الزكاة اليوم أمرٌ مهج، وأداة قوية ومؤثرة في ظل الأزمة التي يشهدها العالم.

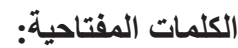

الزكاة، تعجيل، تأجيل، أحكام، آثار.

\section{المقدمة}

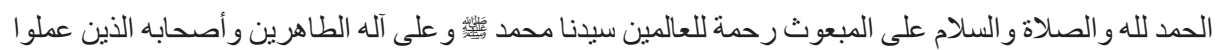
على نشر هذا الدين بالحجة و الاليل الو اضلح الصام المبين أما بعد:

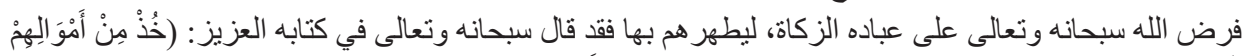

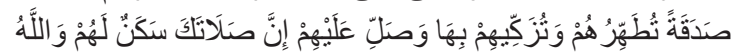

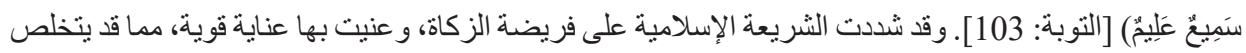

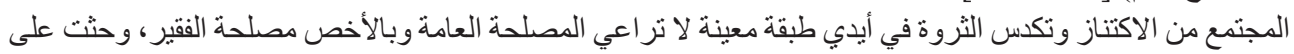

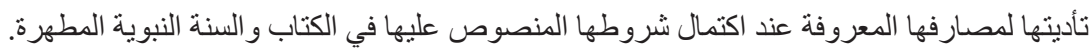

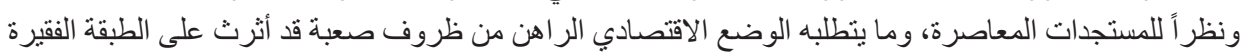

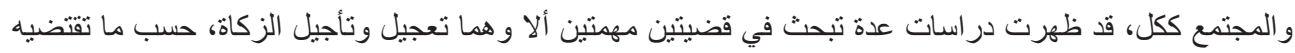

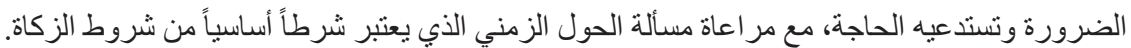

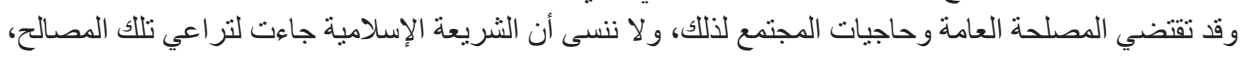

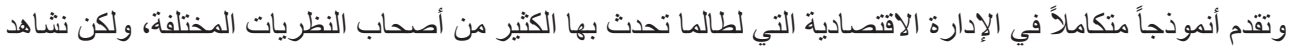

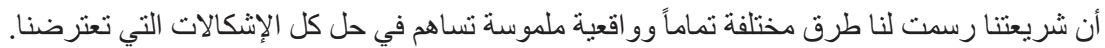

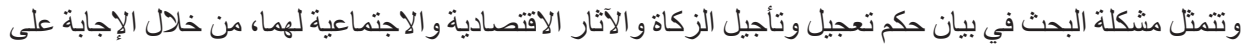

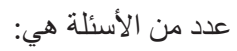

1

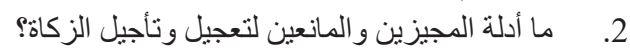

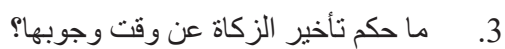

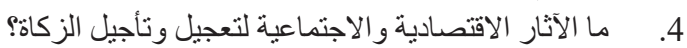

و هدف الدراسة تكمن في بيان حكم تعجيل الزكاة، والخلاف الفقهي بين العلماء، و الر أي الر اجح في المسألة. وبيان

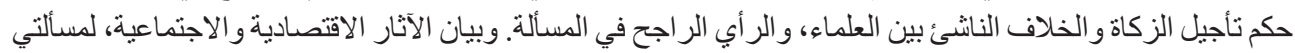

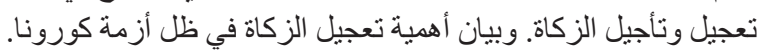

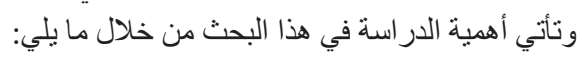

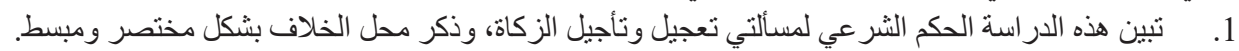

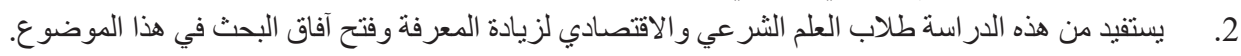

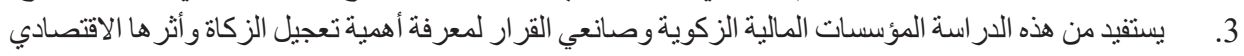
على المجنمع. ولقد أجري هذا البحث في جامعة اليرموك مدينة اربد/ الاردن عام 1441هـ _ ــ 2020م.

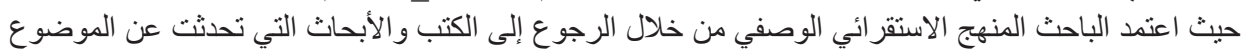
و التعرف على أهمية الزكاة في المجتمع المسلم. 
الدراسات السابقة

من خلال البحث في المصادر العلمية وقو اعد البيانات وفي حدود علم الباحث هذه أبرز الدراسات السابقة:

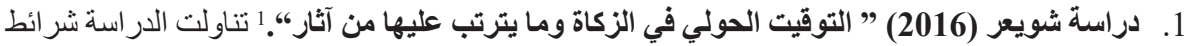

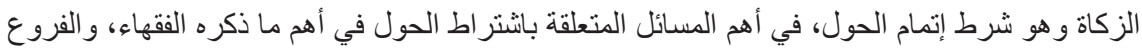

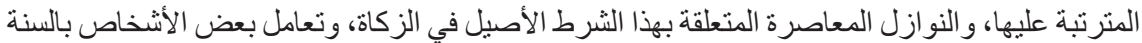

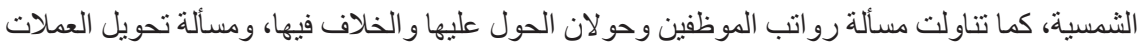

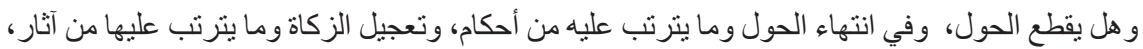

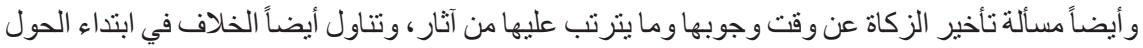

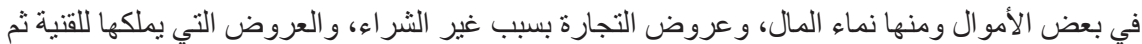

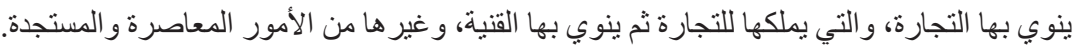

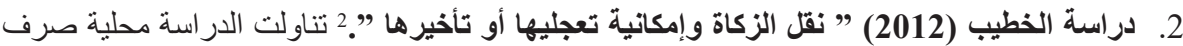

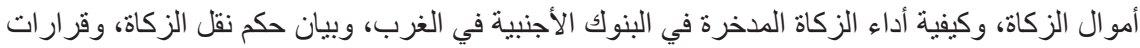

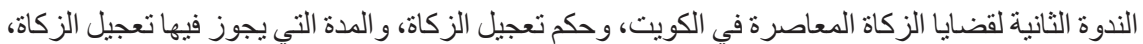

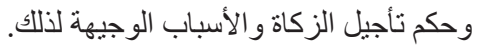

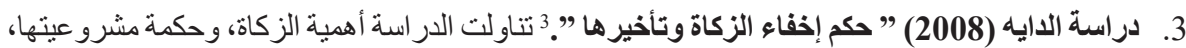
و التر هيب من منعها، وحكم إخفاء الزكاة، ومذاهب العلماء فيه، و أدلة كل مذهب، ومناقثنات الاستدلال بها،

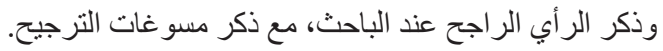

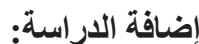

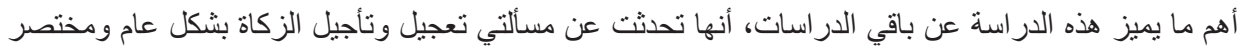

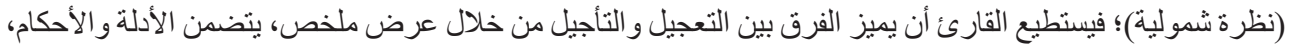
ثم ذكر الآثار على كلتا المسألتين، فقد قام البحث بتغطية الموضو عائ تغطيةً إجمالية يستفيد منها القارئ ويحصر الأفكار في

المبحث الأول: تعجيل الزكاة، الآراء الفقهية والآثار الاقتصادية والاجتماعية.

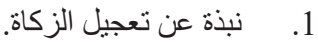

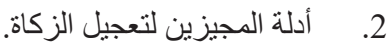
3. أدلة المانعين لتعجيل الزكاة.

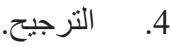
5.

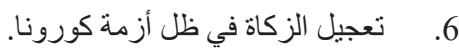
أولاً: نبذة عن تعجيل الزكاة: لقد فرض الله سبحانه وتعالى الزكاة بين المسلمين، و أمر الأغنياء بأن يخرجو ا من أمو الهم

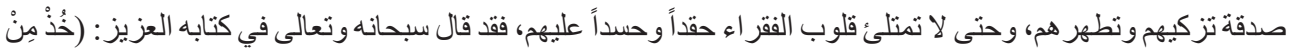




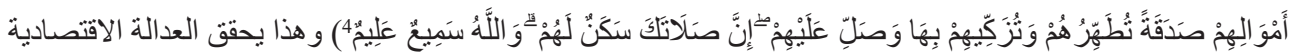

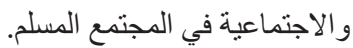
و الأصل أن الزكاة تُخرج في مو عدها المحدد عند اكتمال شروطها المنصوص عليها في الكتاب و السنة النبوية، ومن

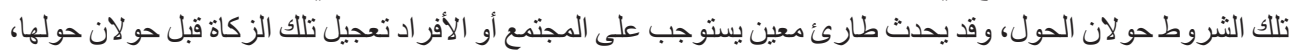

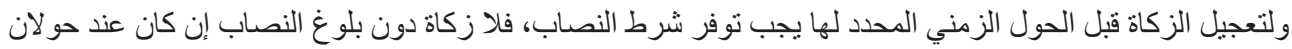

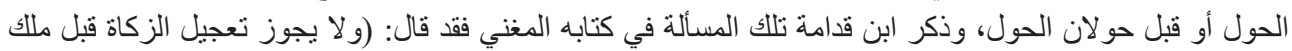

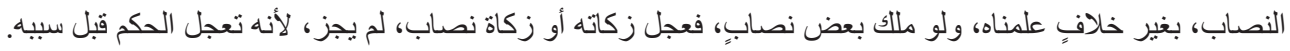

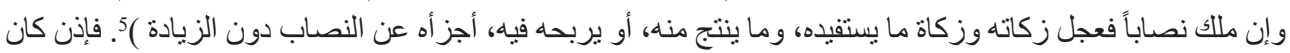

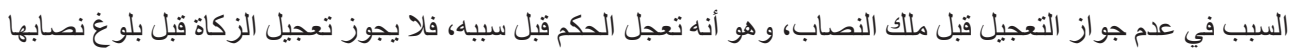

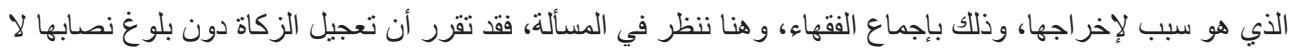

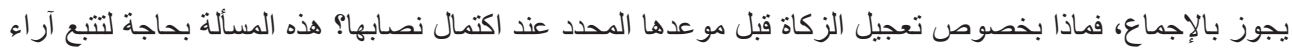

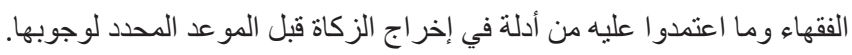

ثانياً: أدلة المجيزين لتعجيل الزكاة: بعدما ذكرنا في المطلب الأول أن التعجيل للزكاة لا يجوز بالإجماع قبل بلوغ

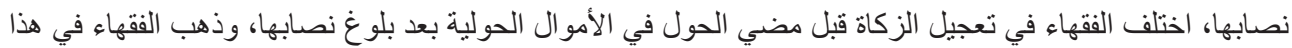

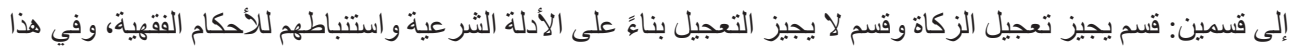

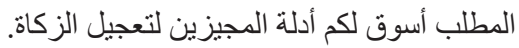

وذهب لجواز تعجيل الزكاة عن الحول جمهور الفقهاء من الحنابلة6، الحنفية7، و الثنافعية3، وهو قول عند المالكية

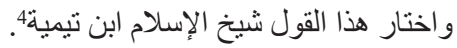

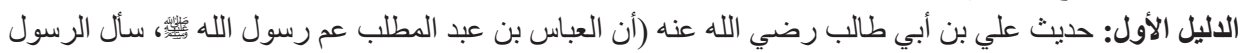

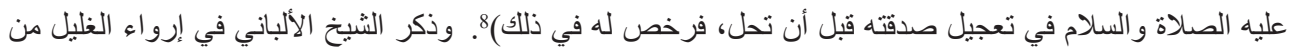

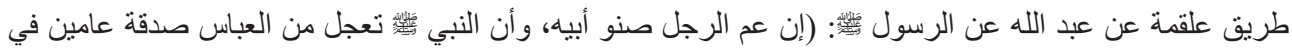

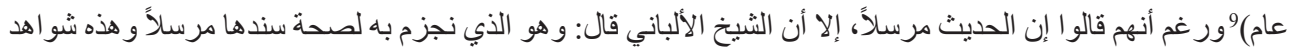

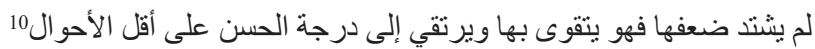

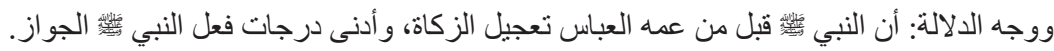

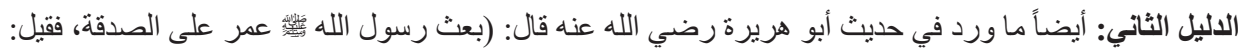

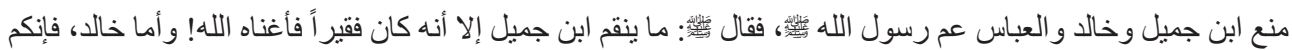

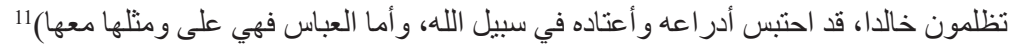

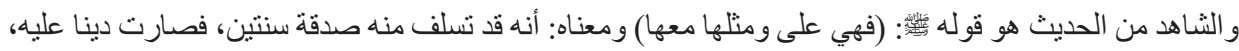

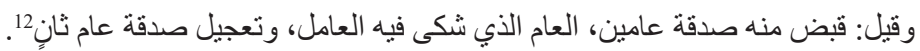

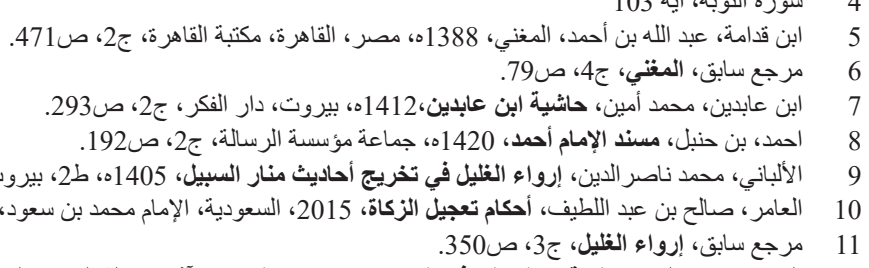

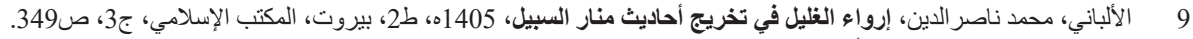

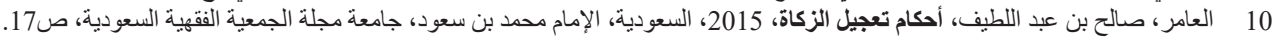
12 الثويعر، عبد السلام، التوقيت الحولي في الزكاة وما يترتب عليها من آثار، مجلة المجمع الفقهي الإسلامي، سنة16، ص15. 


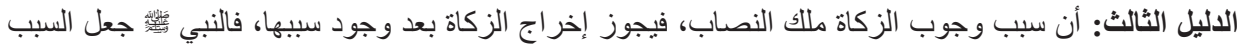

وجود النصاب، و الحول وصفه، لأنه يقوم به كما تقوم الصفة بالموصوف و لا تقوم الصفة بنفسهان.

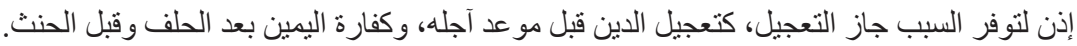

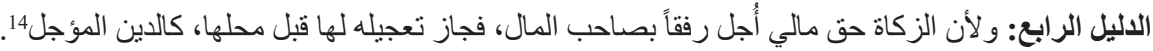

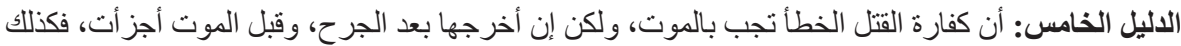
تعجيل الزكاة إن أخرجها قبل الحول15. بقي أن نناقش مسألة وردت عند المجيزين لتعجيل الزكاة، ألا وهي المدة التي يجوز فيها تعجيل الزكاة، فبعضهم أجاز

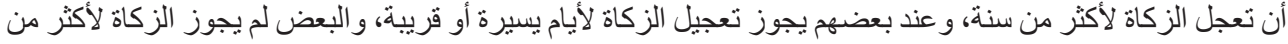

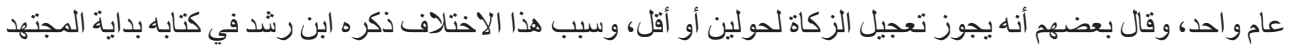

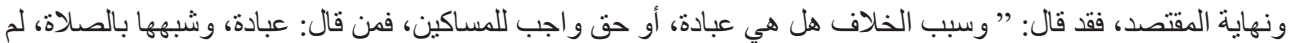

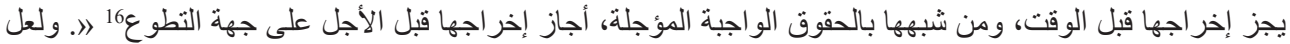

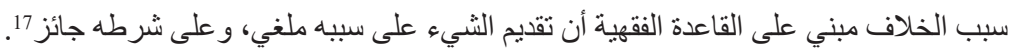

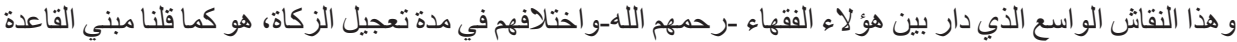

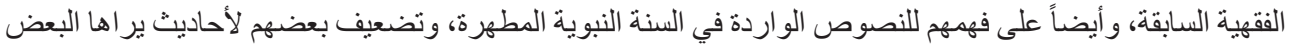

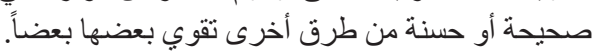

\section{ثالثثاً: أدلة المانعين لتعجيل الزكاة}

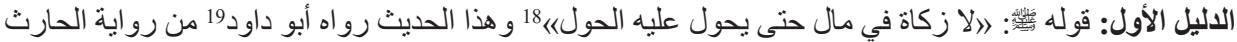

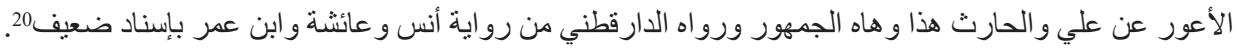

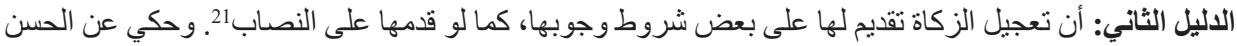

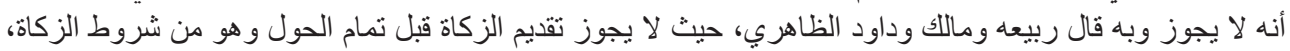

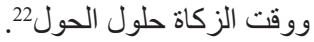

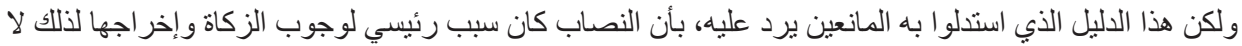

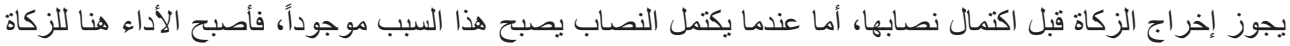

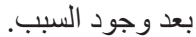
الاليل الثالث: قياس تعجيل الزكاة عن وقت وجوبها على تلع تعجيل الصلاة قبل وقتها، حيث إن لكل منهما وقتاً حدده

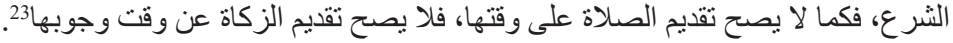

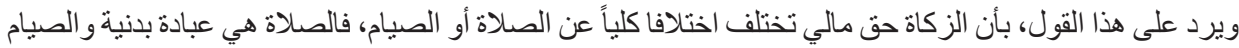

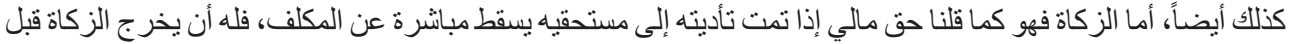

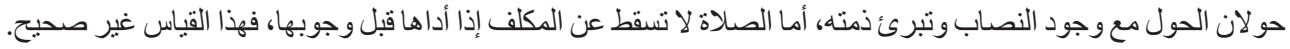

13 الجدعاني، حامد بن حميدان، التعجيل في إخراج الزكاة ـــراسة فقهيةـ، مكة المكرمة، جامعة أم القرى، ص22+23. 14 15

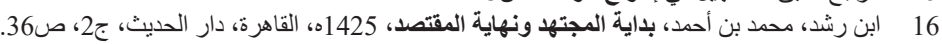

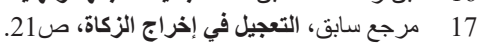

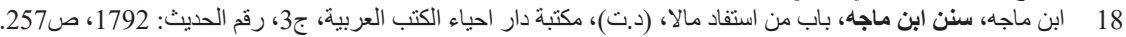

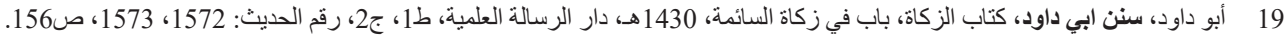

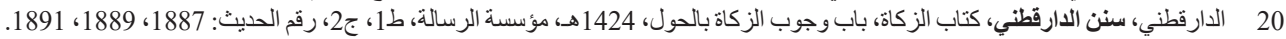

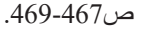


رابعاً: الترجيح: ويمكن القول، بجواز تعجيل الزكاة كما ورد عند المجيزين لتعجيل الزكاة، ومن خلال النظر في الأدلة

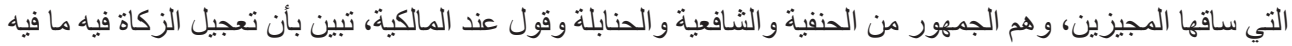
من الحرص على مصالح الفقر اء وتيسير أمور هم، وشريعتنا الإسلامية جاءت لتر اعي مصالح المجتمع وتحقق منطلباته

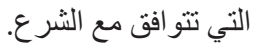

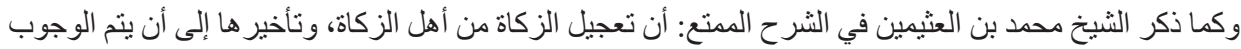

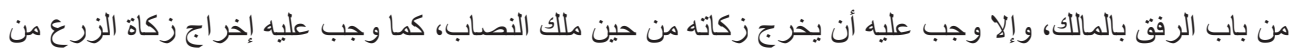

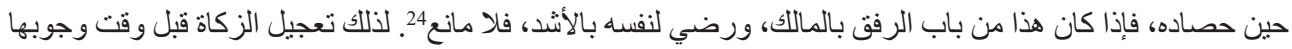

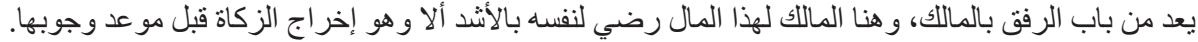

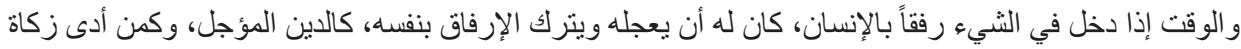

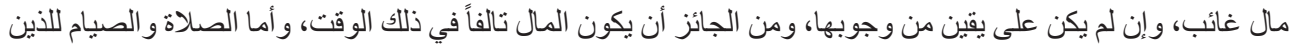

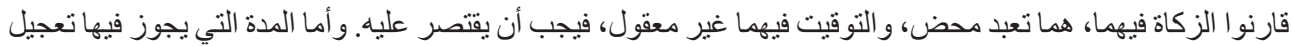

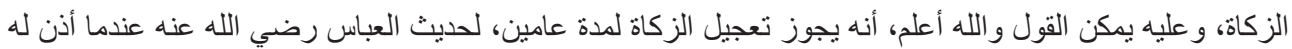

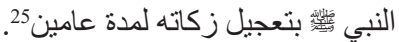

خامساً: الآثار الاقتصادية والاجتماعية لتعجيل الزكاة: لتعجيل الزكاة قبل وقت وجوبها آثار اقتصادية واجتماعية تؤثر

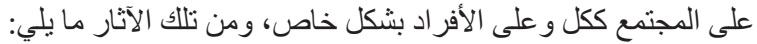

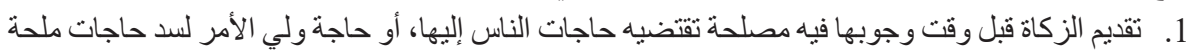

$$
\text { وضرورية، فتقديمها من الأمور الفاضلة. }
$$

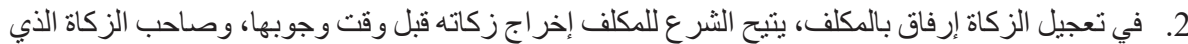

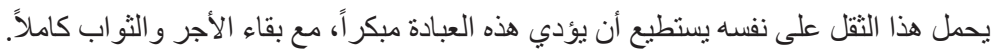

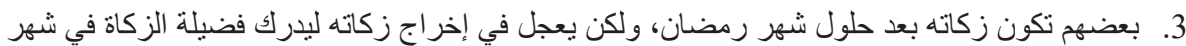

$$
\text { رمضان المبارك. }
$$

4. يزيد عند الفقر اء الميل الحدي للاستهلاك، ويؤدي بدوره إلى زيادة الطلب الفعال، الأمر الذي بترتب عليه

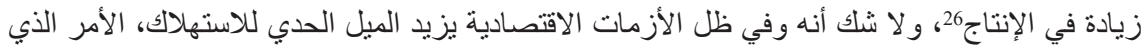
بتطلب دفع النقود إليهم لتفعيل طلبهم الاستهلاكي. 5. يترتب على تعجيل الزكاة في ظل الأزمات زيادة في الاستثمار ، الأمر الذب يؤدي إلى إنقاذ المجتمع الاقتصادي الإني

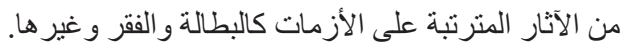

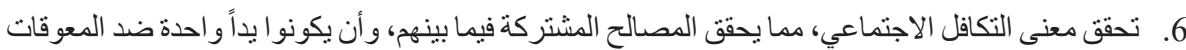

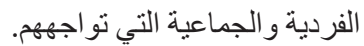
7. نضمن في ظل الأزمات الاقتصادية توفير حد الكفاية بشكل أسر ع لجميع أفر اد المجتمع.

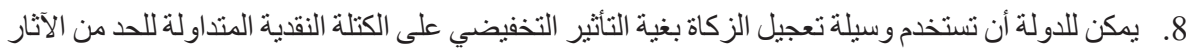
السلبية للتضخم

سادساً: تعجيل الزكاة في ظل أزمة كورونا: تز امناً مع هذا البحث ظهر لدينا في العالم أزمة وبائية تستدعي منا أن نتكلم

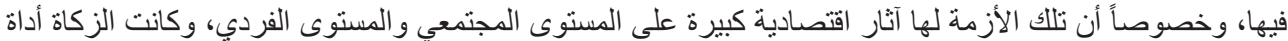


إنقاذ من الوضع الر اهن، ولطالما كنا كثير اً ننادي بتفعيل دور الزكاة في المجتمع بشكل أوسع، وكُتبت العديد من الأبحاث

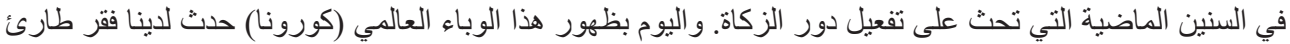

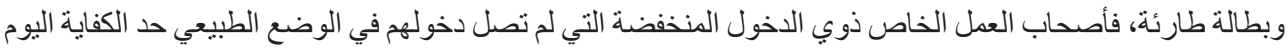

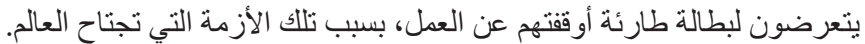

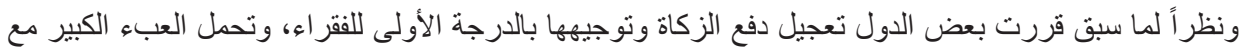
الدولة لمو اجهة أزمة كورونا العالمية.

و ون هذه الدول التي أصدرت فتوى بتعجيل الزكاة المملكة الأردنية الهاشمية، فصدر عن دائرة

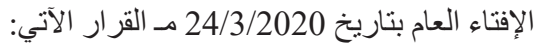

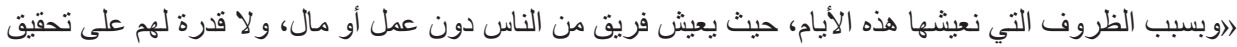

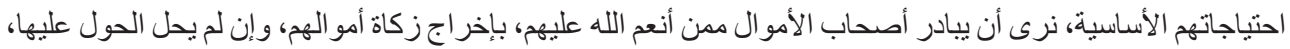

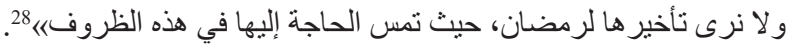

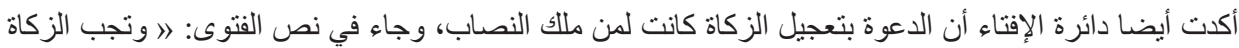

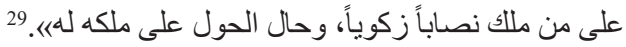
ومن الدول التي أصدرت فتوى بتعجيل الزكاة أيضا، دولة الجزائر الثقيقة بتاريخ 2/4/2020، وجاء في نص الفتوى "ا إن الأصل في إخر اج زكاة الثروة النقدية والحيو انية أن يكون بعد بلوغ النصاب، ودوران الحول (السنة)، غير أنه إنه

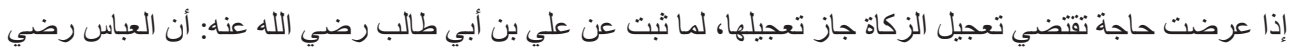

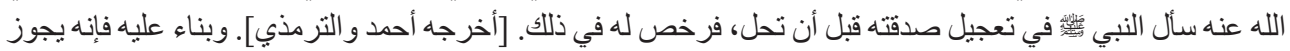

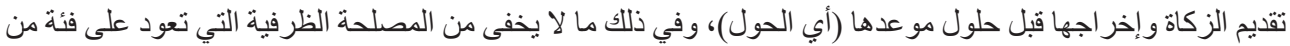

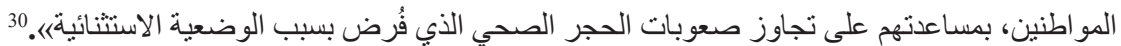

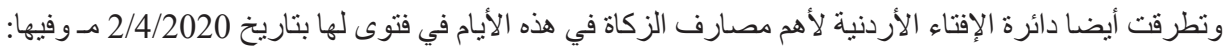

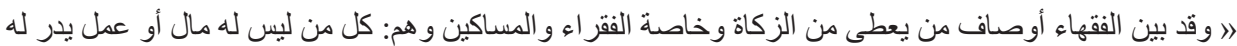

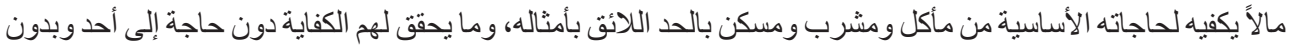

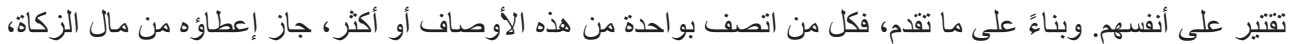

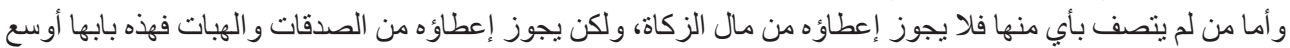

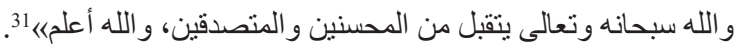

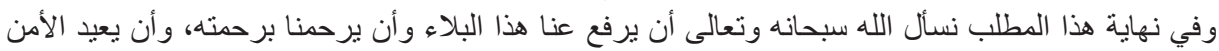
و الاستقر ار لسائر البلاد هو مو لانا فنعم المولى ونعم النصير.

\section{المبحث الثاني: تأجيل الزكاة وآثار ها الاقتصادية والاجتماعية}

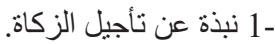
-2 -3 أدلة المانعين لنتأجيل الزكاة. -4 الآثار الاقتصادية والاجنماعية لتأجيل الزكاة. 


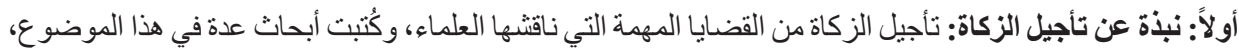

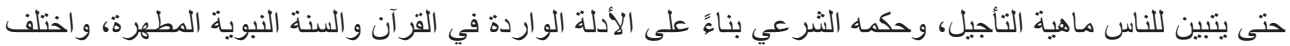

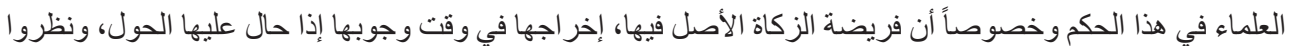

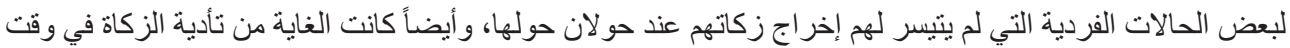

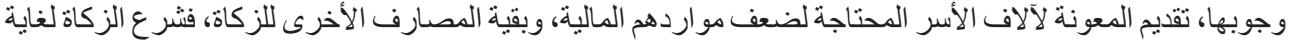

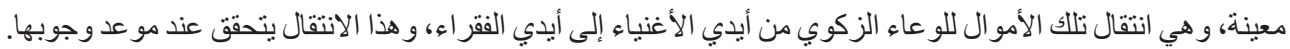

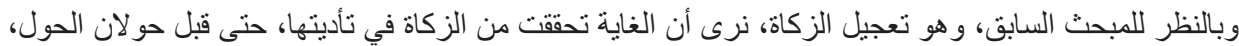

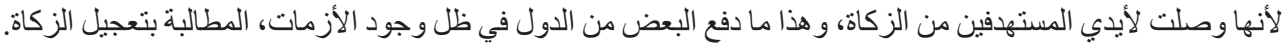

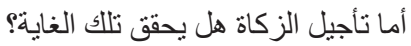
إذن هذا الموضوع بحاجة أيضاً لتتبع آراء الفقهاء، و الأدلة التي اعتمدوا عليها في تخريج المسألة وبيان حكمها، ونحن

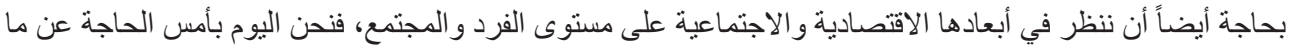

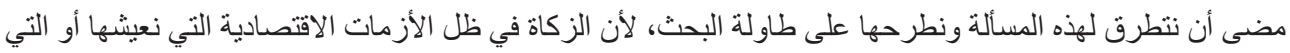

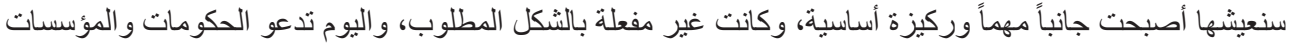

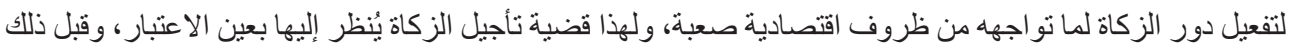

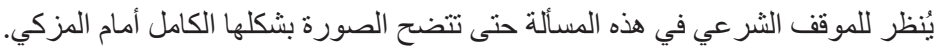

ثانياً: أدلة المجيزين لتأجيل الزكاة: اختلف العلماء في حكم من بلغ النصاب ماله وحال عليه الحول، ثم بعد ذللك قام

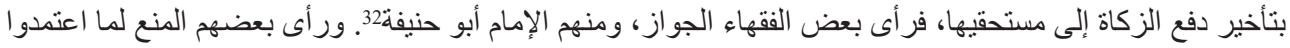

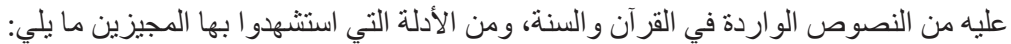

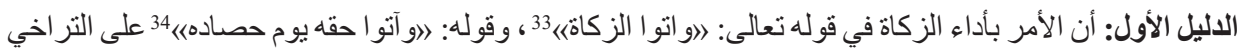

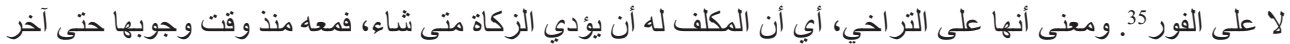
عمره، و هذا هو الأمر المطلق التي قصدته الحنفية. فذهب الحنفية إلى أن صيغة الأمر المطلق عن التقييد الزماني لا تدل على الفور القاضي بطلب الإتيان، وامتثال الفعل

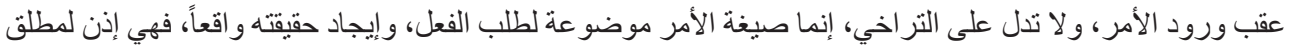

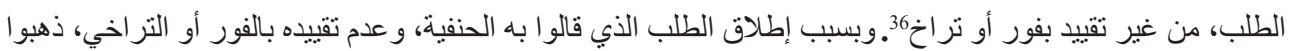

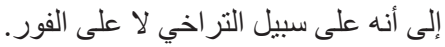

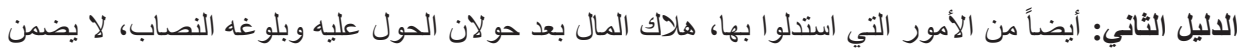

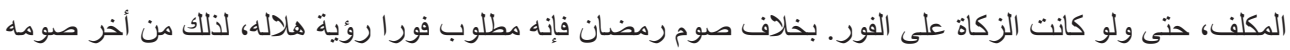
وجب عليه قضاؤه

\section{ثالثثاً: أدلة المانعين لتأجيل الزكاة}

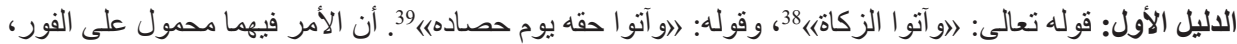

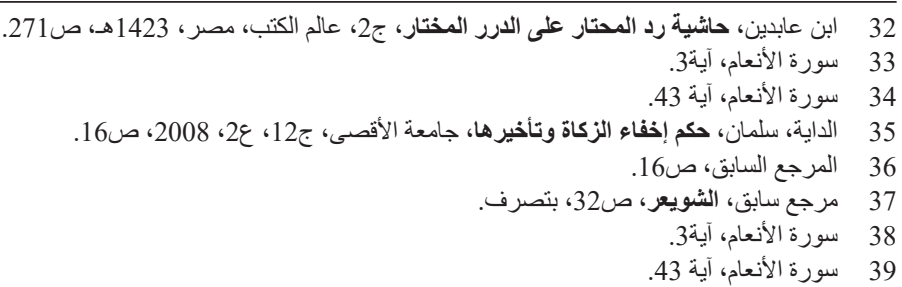


وكذللك في كل أمر مطلق عن قيد التأقيت، أو التحديد بزمن معين، وهو مذهب أكثر المالكية، والحنابلة، وبعض الثافعية و هو من المختار عندنابن.

إذن تأدية الزكاة تكون على الفور ، وليس المقصود في الآيات الكريمة التر اخي، كما قال الحنفية،

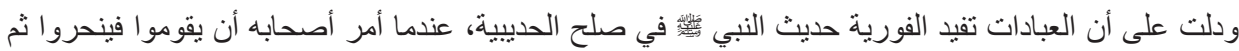
يحلقو ا، ثم بعد ذللك ما قام منهم رجل و احد، و عندما ذكر ما حدث لأم سلمة رضي الله فله عنها، أثنارت عليه أن يقوم فينحر

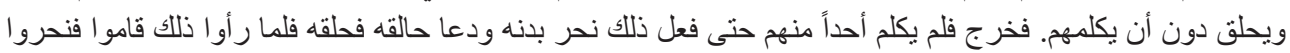
وجعل بعضهم يحلق بعضاً 4

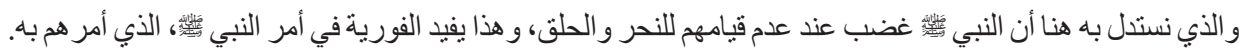

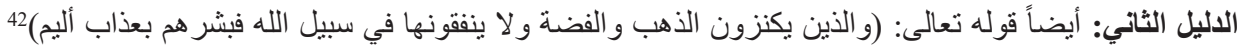

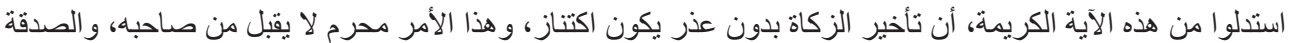

تأخير ها مذموم وفيه مماطلة بالنسبة لمستحقيها.

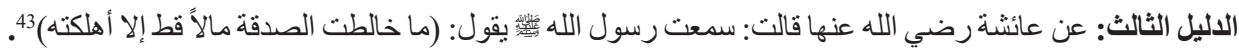

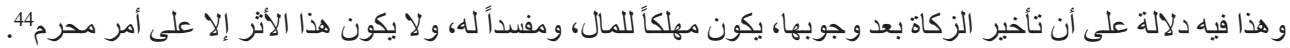

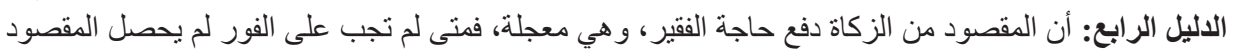

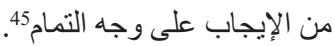
الترجيح: الذي أراه والله أعلم، أن تأجيل الزكاة لغير عذر أمر لا يجوز شرعاً، وبهذا يكون قد أخر عبادة كلفه الله الهابه

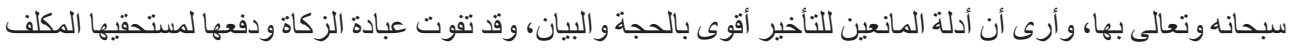

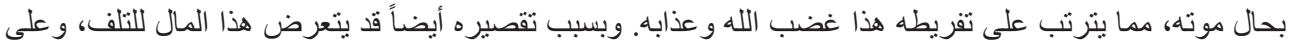

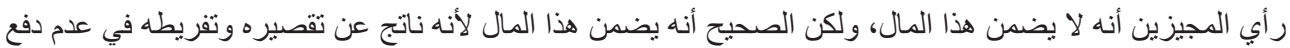

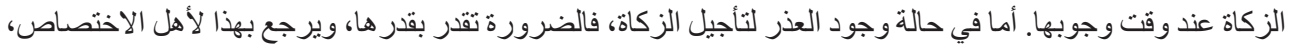

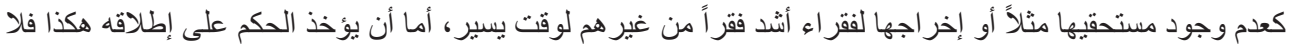

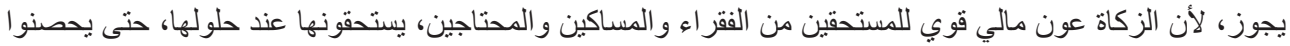
أنفسهم من مد أيديهم للناس، و لا شك أيضاً أن إخر اج الزكاة في وقتها أنفع للمكلف من تر اكم الو اجبات عليه، ومن عجزه ونه مستقبلاً عن ادائها.

\section{رابعاً: الآثار الاقتصادية والاجتماعية لتأجيل الزكاة}

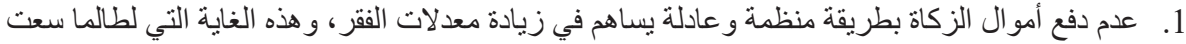

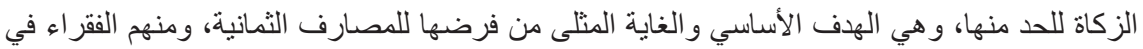

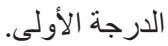
2. قد ينشأ عن تأجيل الزكاة، انتشار البغضاء بين الفقير و الغني، لأن الفقير سيشعر وقتها بأنه مُنع من حق له ضمنته الثريعة الإسلامية. 3. أيضاً الزكاة تعد دورية، ففي كل سنة يعتاد الفقير على أخذها من المكلف، وتأخير الزكاة عن وقتها يُحدث خلل في النمط الاستهلاكي لمستحقيها.

$$
\begin{aligned}
& \text { 40 } 40 \\
& 41 \text { العسقلاني، أحمد بن علي، فتح الباري شرح صحيح البخاري، 1407، دار الريان للتراث، ج5، ص388. }
\end{aligned}
$$

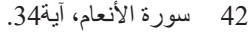

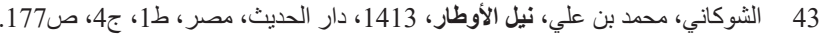

$$
\begin{aligned}
& 44
\end{aligned}
$$

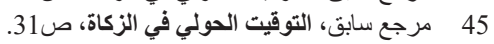


4. قديؤدي تأخبر الزكاة عن وقتها، لاختلاط الأمو ال بعضها ببعض، فيصبح من الصعب على صاحبها أن يفرق

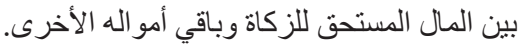

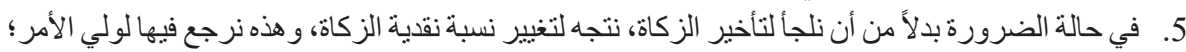

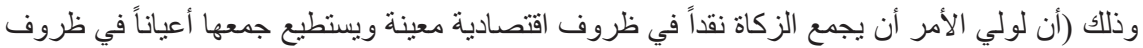

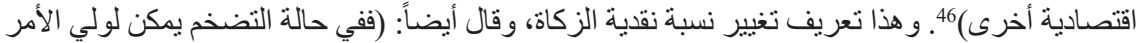

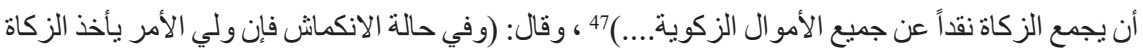

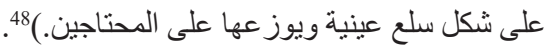

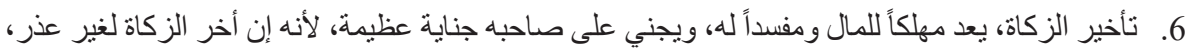

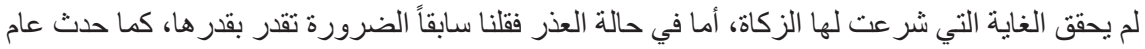
الرمادة. هذه الآثار التي تم ذكرها تبين الأمور السلبية التي تلحق بتأخير الزكاة.

الخاتمة الحمد لله في البدء و الختام، و الصلاة و السلام على رسوله، و على آله وأصحابه الكر ام. وبعد فهذه أهم النتائج التي تم التوصل إليها في هذا البحث:

1. أن الر اجح في مسألة تعجيل الزكاة بعد بلوغ النصاب هو الجواز ، أما قبل بلوغ النصاب النصاب فلا يجوز.

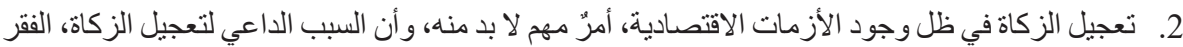
الطارئ و البطالة الطارئة.

3. تعجيل الزكاة قبل وقت الوجوب، لها آثار اقتصادية واجنماعية، تؤثر على المجتمع ككل، و على الأفر اد بشكل

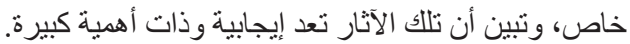

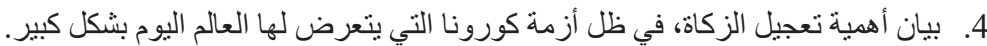

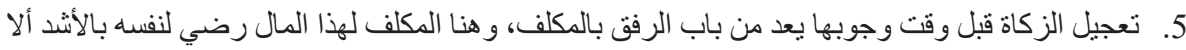

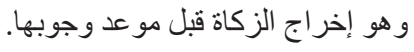

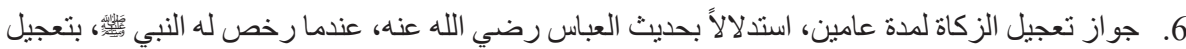
زكاته عن عامين. 7. تأجيل إخر اج الزكاة بعد حلول الحول عليها، وبلو غها النصاب، أمرٌ محرم، لغير عذر شرعي، أما في حالة

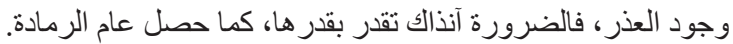

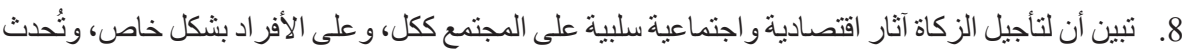
خلل في النمط الاستهلاكي لمستحقيها. 9. ويقتر ح في حال دعت الضرورة الاقتصادية إلى تأخير الزكاة، أن نتجه إلى تغيير نسبة نقدية الزكاة، بدلاً من

$$
\text { تأخير ها. }
$$

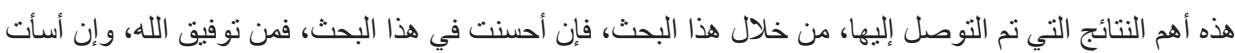

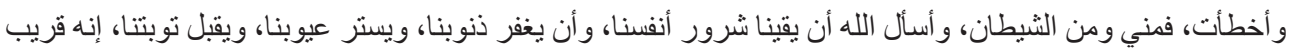
مجيب، و آخر دعو انا أن الحمد لله رب الني العالمين. 


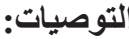

• ضرورة محاكاة الجهات المختصة لتعجيل الزكاة في ظل الأزمات الاقتصادية، وخصوصا في ظل ما خلفته

$$
\text { أزمة كورونا. }
$$

• ضرورة تفعيل آلية تعجيل الزكاة كأداة من أدوات السياسة النقدية، وذلك لما تنتركه من آثار إيجابية على التى

$$
\text { الاقتصاد الكلي في ظل الجو ائح؛ كجائحة كورونا. }
$$

• مر اجعة مسائل تأجيل اخر اج الزكاة و النظر فيها ومر اعاة وجود الأعذار و الضرور ات من خلال إعادة قر اءة

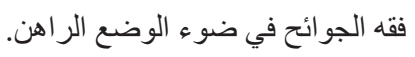

Peer-review: Externally peer-reviewed.

Conflict of Interest: The authors have no conflict of interest to declare.

Grant Support: The authors declared that this study has received no financial support.

\section{References}

\section{قائمة المصادر والمراجع}

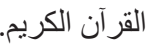

ابن قدامة، عبد الله بن أحمد، المغني، 1388ه، مصر، القاهرة، مكتبة القاهرة، ج2.

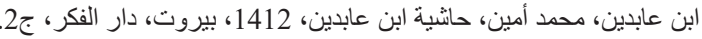
ابن تيمية، أحمد عبد الحليم، مجموع الفتاوى، 1416، المدينة، مجمع الملك فهد لطباعة المصحف الثريف.

أحمد بن حنبل، مسند الإمام أحمد، 1420، جماعة مؤسسة الرسالة، ج2.

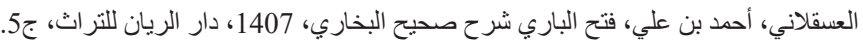

ابن عابدين، محمد أمين، حاثية رد المحتار على الدرر المختار، 1423، مصر، عالم الكتب، ج2.

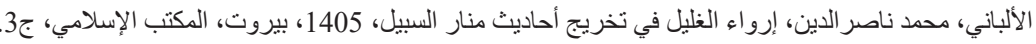

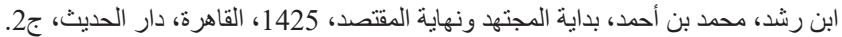

ابن ماجه، سنن ابن ماجه، باب من استفاد مالا، (د.ت)، مكتبة دار احياء الكتب العربية، ج3.

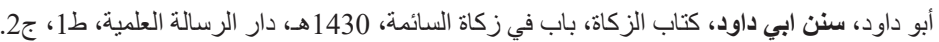

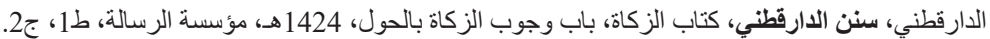
الثويعر، عبد السلام، التوقيت الحولي في الزكاة وما يترثب عليها من آثار ، مجلة المجمع الفقهي الإسلامي، 2016.

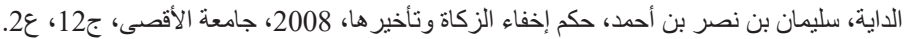

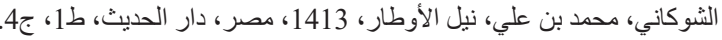

العامر ، صالح بن عبد اللطيف، أحكام تعجيل الزكاة، 2015، السعودية، مجلة الجمعية الفقهية السعودية.

الجدعاني، حامد بن حميدان، التعجيل في إخر اج الزكاة ـدر اسة فقهية-، مكة المكرمة، جامعة أم القرى. عبادة، إبر اهيم عبد الحليم، السياسة النقدية ضو ابطها وموجهاتها في اقتصاد إسلامي، 2011، اربد، جاند، جامعة البرموك. اللاوي، عقبة، فوزي محيريق، نمذجة الآثار الاقتصادية للزكاة، 2011.

الخطيب، محمود، نقل الزكاة و إمكانية تعجيلها أو تأخير ها، 2012، وزارة الأوقاف و الثؤون و المقدسات الإسلامية.

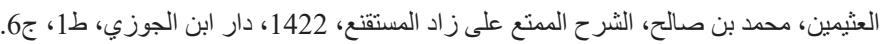

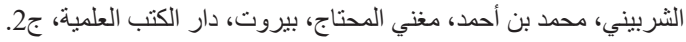
دار الإفتاء الأردنية، جواز إخر اجزئن زماة المال قبل حولان الحول: https://www.aliftaa.jo/Question2.aspx?QuestionId=3566\#.XpTeSJm8aDY وزارة الثؤون الدينية والأوقاف، الجزائر، جواز تعجيل الزكاة: https://www.aliftaa.jo/Question2.aspx?QuestionId=3568 
